Revue d'histoire de l'Amérique française

REYUE D.HISTOIRE DE L'AMÉRIQUE FRANÇAISE

\title{
ANGERS, Lorenzo, Chicoutimi - Poste de traite 1676-1856. Préface de Félix-Antoine Savard. Collection historique. Les Éditions Leméac, 1971. 125 p. Index, ill. \$3.00.
}

\section{Roger Le Moine}

Volume 25, numéro 1, juin 1971

URI : https://id.erudit.org/iderudit/303047ar

DOI : https://doi.org/10.7202/303047ar

Aller au sommaire du numéro

Éditeur(s)

Institut d'histoire de l'Amérique française

ISSN

0035-2357 (imprimé)

1492-1383 (numérique)

Découvrir la revue

Citer ce compte rendu

Le Moine, R. (1971). Compte rendu de [ANGERS, Lorenzo, Chicoutimi - Poste de traite 1676-1856. Préface de Félix-Antoine Savard. Collection historique. Les Éditions Leméac, 1971. 125 p. Index, ill. \$3.00.] Revue d'histoire de l'Amérique française, 25(1), 114-115. https://doi.org/10.7202/303047ar d'utilisation que vous pouvez consulter en ligne.

https://apropos.erudit.org/fr/usagers/politique-dutilisation/ 


\section{COMPTES RENDUS}

ANGErs, Lorenzo, Chicoutimi - Poste de traite 1676-1856. Préface de Félix-Antoine Savard. Collection historique. Les Editions Leméac, 1971. 125 p. Index, ill. $\$ 3.00$.

On ne dira jamais assez l'utilité des monographies, surtout quand elles sont bien faites, comme c'est ici le cas. Quel chercheur s'intéressant à un personnage ou à une période, n'a pas glané dans ce genre d'ouvrages, ce qu'il avait vainement chercher ailleurs? Avec Chicoutimi, Poste de Traite (1676-1856), l'abbé Angers nous raconte les origines d'un établissement voué à un essor considérable, et ce, jusqu'au moment où il sera doté d'institutions qui en feront la métropole d'une vaste et riche région. Grâce à une méthode consciencieuse, l'auteur a su tirer tout le parti possible d'une documentation assez mince et d'un abord souvent difficile. Plusieurs documents ont été rédigés en latin. Cela mérite d'être souligné à une époque où la pratique des "langues mortes" tend à disparaître.

Chicoutimi naquit au XVII e siècle, grâce aux efforts des Jésuites et des commerçants. Dès le début, on retrouve associés à son développement, quelques-uns des grands noms de l'histoire de la Nouvelle-France. Ainsi, les Pères Albanel, Crespieul, Coquart, La Brosse, Laure; les entrepreneurs Charles Bazire, Nicolas Juchereau de Saint-Denis, Michel Le Neuf de la Vallière, François Chavigny de la Chevrotière, Denis Riverin, Pierre Bécart de Grandville, Paschal-Jacques Taché. Si Bazire peut être considéré comme le fondateur de l'endroit, le Père Laure joua un rôle dont on ne dira jamais assez les mérites. On lira avec intérêt les pages qu'il consacra à l'état de la mission. Les rivalités entre bourgeois ne tardèrent pas à naître et à se développer. La concession, le poste, passa à divers adjudicataires. Et les commis rivalisèrent d'astuce pour attirer à eux les Indiens. Là comme ailleurs, l'eau-de-vie fit ses ravages et les missionnaires tonnèrent. Puis, apparurent des institutions qui donnèrent au poste sa stabilité tout en amorçant sa transformation. Une église fut construite de même que des magasins. Un petit village se forma. Et un prêtre s'y installa à demeure. L'histoire de Chicoutimi, à l'époque, c'est, avec ses hauts et ses bas, l'histoire de la Nouvelle-France en résumé.

Les Anglais n'attendirent pas que toute la colonie soit conquise pour s'emparer des fourrures du poste. Et, s'ils chassèrent les anciens occupants, ce fut dans le but de marcher sur leurs traces. Les hommes changent mais la traite se poursuit. Sauf que la vie agricole, qui avait été à peu près nulle sous l'Ancien Régime, commença à se développer en dépit de l'hostilité des nouveaux maîtres qui savaient bien que la culture du sol réduirait peu à peu leur champ d'action et, partant, leur commerce. En 1837, des fils de la Malbaie formèrent la Société des Vingt-et-un (les terres arables de Charlevoix étant toutes occupées, ils devaient chercher à s'établir ailleurs). Avec la colonisation du Saguenay, l'histoire de cette région prend un départ nouveau, d'autant que l'industrie du bois commence également à se développer. A partir de ce moment, Chicoutimi cesse d'être un poste.

L'ouvrage de l'abbé Angers est d'une lecture agréable. Les notes, judicieuses et nombreuses, ne déparent pas le texte. De sorte qu'il est

RHAF, vol. 25, no 1 (juin 1971) 
susceptible de satisfaire à la fois les spécialistes de l'histoire et les amateurs. Signalons également de beaux hors-textes comme cette carte du Saguenay datant de 1748, et que Mademoiselle Monique de la Roncière a exposée au pavillon de la France, à Expo 67. De même, d'intéressantes pages sur les moyens de communication d'alors, "par les chemins qui marchent". En tournant la dernière page, on regrette que $M$. Angers n'ait pas débordé son sujet et qu'il n'ait pas poursuivi l'histoire de Chicoutimi. Serait-ce dans ses projets? Nous le souhaitons vivement.

Université d'Ottawa

ROGER LE MOINE Ottawa 